\title{
Single-phase On-board Integrated Battery Charger Based on a Nine-phase Machine
}

\author{
N. Bodo, I. Subotic, E. Levi, M. Jones \\ Liverpool John Moores University \\ Liverpool, U.K.
}

\begin{abstract}
An obvious obstacle to a wider utilization of electric vehicles (EVs) is the absence of a widely available charging network. Direct charging of $\mathrm{EV}$ batteries with dc voltage in charging stations requires deployment of expensive power electronics equipment. On the other hand, placing the same equipment on-board an EV would enable access to any three-phase grid outlet, but would substantially increase the vehicle cost, weight and volume. A multitude of solutions have been proposed to integrate the charger using the already existing equipment, which normally serves the propulsion operating mode of the vehicle. However, only a few of them have the advantage of torque-free fast charging that is accomplished without any hardware reconfiguration. The primary aim of these integrated on-board chargers is to provide fast charging by enabling connection to a three-phase grid. These structures also enable slower charging by connection to a single-phase grid. This paper examines single-phase charging capabilities of an integrated charger using a nine-phase machine. The charger does not require any reconfiguration or additional elements other than those used in propulsion mode and it does not produce torque during the charging. Additionally, the charger can provide energy recuperation to the grid. The operating principle relies on additional degrees of freedom of multiphase machines, to draw currents through non-flux and non-torque producing planes of the machines.
\end{abstract}

Keywords - Battery chargers, electric vehicles, integrated onboard charger, multiphase machines

\section{INTRODUCTION}

Due to the environmental, economic and climate change factors, major change in the transportation systems appear to be inevitable in the near to mid future. Although innovative concepts for electric vehicles are constantly being developed by all major manufacturers, the main challenges remain the same as they were more than a century ago, when the first electrical cars were introduced. These are the high battery weight and limited driving range, resulting in a lack of charging station infrastructure. Wide charging infrastructure availability is realistic only if the existing single-phase/threephase grid outlets can be used for this purpose.

If connection to an existing ac grid outlet is to be achieved, chargers have to be situated on-board the vehicles. The widely available single-phase grid can be used for slow charging in this way, while three-phase outlets can be used for fast charging. Fast charging from the ac grid can be accomplished without any additional off-board electronics or specialized charging stations, unlike the charging from a dc charging station. However, such non-integrated on-board chargers add

The authors would like to acknowledge the Engineering and Physical Sciences Research Council (EPSRC) for supporting the Vehicle Electrical Systems Integration (VESI) project (EP/I038543/1). to the cost, weight and take space in the car. An optimal solution is therefore to integrate the already existing power components, which are already utilized for the vehicle propulsion, into the battery charging process. The machine that is used for propulsion serves usually as a filter in these chargers. An additional requirement for integrated on-board battery chargers is that they do not produce torque in the machine during charging.

A few integrated battery chargers have been proposed to date, which are capable of fast, three-phase charging without torque production. A three-phase machine operated in an open-end winding configuration during charging is considered in [1]. The mid-points of three phases of the machine are then connected to the three-phase grid. Since the current in each pair of the machine's phase half-windings is the same while half-windings are in spatial opposition, there is no flux and torque production in the machine. The three-phase machine with access to the phase mid-points is essentially a symmetrical six-phase machine. This solution is currently being considered for use in future EVs by Valeo [2].

Somewhat different solutions with an asymmetrical and symmetrical six-phase machine were proposed in [3, 4], which are based on the phase transposition principle [5]. They have the advantage of torque-free operation, but require hardware reconfiguration.

If a three-phase machine is used for propulsion purposes, the only available integrated torque-free solution is the one used in the Renault Zoe. It can charge the battery from both the single-phase and the three-phase grid, without torque production in the machine, and it appears that it relies on patents $[6,7]$. The charger of $[6,7]$ requires a separate threephase rectifier, which represents an additional non-integrated power electronic converter in the EV. The dc side of the rectifier is connected between the negative dc-rail of the inverter and the neutral point of the three-phase machine. The machine is therefore used as a filtering inductance for the inverter. The inverter serves in charging mode as a dc-dc converter, supplying power to the battery. However, the additional converter has to be rated for the charging power, and this has a negative impact on the size and cost, and spare space in the vehicle.

A different, multiphase machine based, configuration is discussed in [8]. A nine-phase (symmetrical or asymmetrical) machine is used for the propulsion and charging modes. The machine has three isolated neutral points, which are directly connected to the three-phase grid in the charging mode. The converter is controlled in such a way that the same currents 


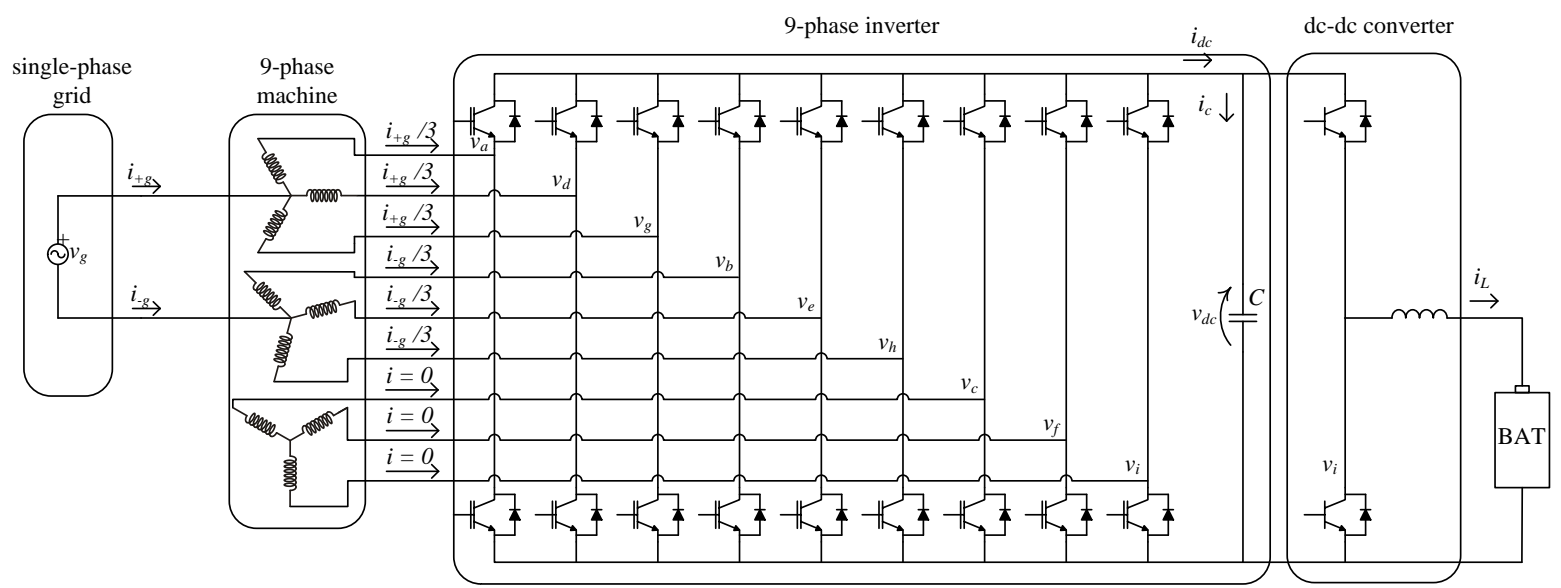

Fig. 1. Topology of the nine-phase integrated on-board battery charger for single-phase grid connection (no galvanic isolation).

flow in all phases of each three-phase winding, leading to zero torque production. $\mathrm{V} 2 \mathrm{G}$ operation is easily achievable with this topology, without any hardware reconfiguration.

Although single-phase charging is inferior to three-phase charging, it is beneficial to have this option available as well, because of the wide availability of single-phase connection points. Some of the surveyed topologies can realize singlephase charging without reconfiguration. This is the case for the solutions with the six-phase symmetrical machine in $[1,2,9]$ Renault's charger is also capable of single-phase charging and $[6,7]$ also offer the possibility of single-phase charging. There is further a number of integrated chargers that are aimed at single-phase charging only [10-16] but cannot be used for fast three-phase charging.

This paper focuses on the single-phase charging using the topologies based on nine-phase symmetrical $\left(40^{\circ}\right.$ spatial shift between any two consecutive phases) and asymmetrical $\left(20^{\circ}\right.$ shift between first phases of consecutive three-phase windings) machines. As noted already, such a topology has been found to be well suited for the three-phase fast charging [8]; adding the single-phase slow charging capability further enhances the versatility of the system.

\section{ThEORETICAL ANALYSIS}

The charging using nine-phase machines is based on connection of the single-phase grid to two of the available three neutral points. The topology of the integrated charger system, with a connection to a single-phase grid, is shown in

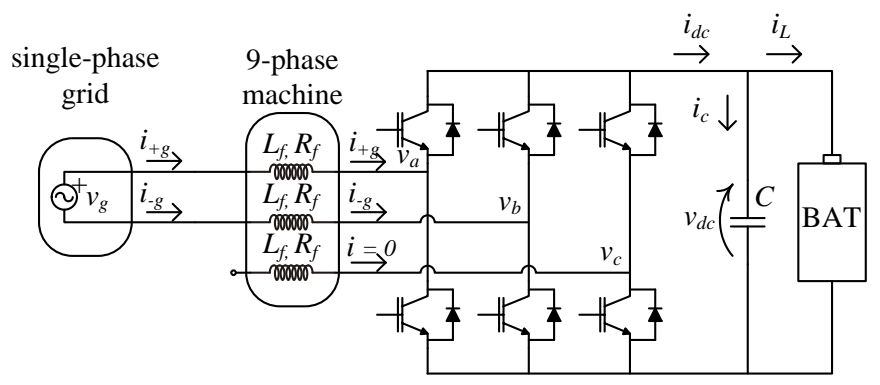

Fig. 2. Equivalent charging/V2G scheme (without a dc-dc converter).
Fig. 1. Three legs of the nine-phase inverter are controlled simultaneously and three phases of the machine are connected in parallel (star connection). Therefore, it is possible to form an equivalent scheme of the machine, with the impedances that are three times smaller than individual phase resistance and leakage inductance. The equivalent scheme is shown in Fig. 2. Since the dc-dc converter in Fig. 1 has no impact on the operating principles of the topology, it is omitted from considerations further on.

The decoupling transformation for an asymmetrical ninephase machine with a single neutral point is given with:

$$
\begin{gathered}
\underline{i}_{\alpha \beta}=\sqrt{2 / 9}\left(i_{a}+\underline{a} i_{b}+\underline{a}^{2} i_{c}+\underline{a}^{6} i_{d}+\underline{a}^{7} i_{e}\right. \\
\left.+\underline{a}^{8} i_{f}+\underline{a}^{12} i_{g}+\underline{a}^{13} i_{h}+\underline{a}^{14} i_{i}\right) \\
\underline{i}_{x 1 y 1}=\sqrt{2 / 9}\left(i_{a}+\underline{a}^{3} i_{b}+\underline{a}^{6} i_{c}+\underline{a}^{0} i_{d}+\underline{a}^{3} i_{e}\right. \\
\left.+\underline{a}^{6} i_{f}+\underline{a}^{0} i_{g}+\underline{a}^{3} i_{h}+\underline{a}^{6} i_{i}\right) \\
\underline{i}_{x 2 y 2}=\sqrt{2 / 9}\left(i_{a}+\underline{a}^{5} i_{b}+\underline{a}^{10} i_{c}+\underline{a}^{12} i_{d}+\underline{a}^{17} i_{e}\right. \\
\left.+\underline{a}^{4} i_{f}+\underline{a}^{6} i_{g}+\underline{a}^{11} i_{h}+\underline{a}^{16} i_{i}\right) \\
\underline{i}_{x 3 y 3}=\sqrt{2 / 9}\left(i_{a}+\underline{a}^{7} i_{b}+\underline{a}^{14} i_{c}+\underline{a}^{6} i_{d}+\underline{a}^{13} i_{e}\right. \\
\left.\quad+\underline{a}^{2} i_{f}+\underline{a}^{12} i_{g}+\underline{a}_{h}+\underline{a}^{8} i_{i}\right) \\
i_{0}=\sqrt{1 / 9}\left(i_{a}-i_{b}+i_{c}+i_{d}-i_{e}+i_{f}+i_{g}-i_{h}+i_{i}\right)
\end{gathered}
$$

where $a=\exp (j \pi / 9)$, indices $\alpha, \beta$ denote the components in the flux/torque producing plane, and indices $x, y$ stand for components in the non-flux/torque producing planes. For the charging connections of Fig. 1 the following holds true:

$$
i_{a}=i_{d}=i_{g}=i_{+g} / 3 \quad i_{b}=i_{e}=i_{h}=i_{-g} / 3 \quad i_{c}=i_{f}=i_{i}=0
$$

The grid currents are given with:

$$
i_{+g}=\sqrt{2} I \cos (\omega t) \quad i_{-g}=-\sqrt{2} I \cos (\omega t)
$$

Substitution of (2) and (3) into (1) gives the following 2D space vectors in the planes of the multidimensional system:

$$
\begin{array}{lrl}
\underline{i}_{\alpha \beta}=0 & \underline{i}_{x 2 y 2}=0 & \underline{i}_{x 3 y 3}=0 \\
\underline{i}_{x 1 y 1}=I(0.33-j 0.577) \cos (\omega t) & i_{0}=\frac{\sqrt{8}}{3} I \cos (\omega t)
\end{array}
$$


The decoupling transformation for the symmetrical ninephase machine is given with:

$$
\begin{gathered}
\underline{i}_{\alpha \beta}=\sqrt{2 / 9}\left(i_{a}+\underline{a}_{b}+\underline{a}^{2} i_{c}+\underline{a}^{3} i_{d}+\underline{a}^{4} i_{e}\right. \\
\left.+\underline{a}^{5} i_{f}+\underline{a}^{6} i_{g}+\underline{a}^{7} i_{h}+\underline{a}^{8} i_{i}\right) \\
\underline{i}_{x 1 y 1}=\sqrt{2 / 9}\left(i_{a}+\underline{a}^{2} i_{b}+\underline{a}^{4} i_{c}+\underline{a}^{6} i_{d}+\underline{a}^{8} i_{e}\right. \\
\left.+\underline{a}^{10} i_{f}+\underline{a}^{12} i_{g}+\underline{a}^{14} i_{h}+\underline{a}^{16} i_{i}\right) \\
\underline{i}_{x 2 y 2}=\sqrt{2 / 9}\left(i_{a}+\underline{a}^{3} i_{b}+\underline{a}^{6} i_{c}+\underline{a}^{9} i_{d}+\underline{a}^{12}\right. \\
\left.i_{e}+\underline{a}^{15} i_{f}+\underline{a}^{18} i_{g}+\underline{a}^{21} i_{h}+\underline{a}^{24} i_{i}\right) \\
\underline{i}_{x 3 y 3}=\sqrt{2 / 9}\left(i_{a}+\underline{a}^{4} i_{b}+\underline{a}^{8} i_{c}+\underline{a}^{12} i_{d}+\underline{a}^{16} i_{e}\right. \\
\left.\quad+\underline{a}^{20} i_{f}+\underline{a}^{24} i_{g}+\underline{a}^{28} i_{h}+\underline{a}^{32} i_{i}\right) \\
i_{0}=\sqrt{1 / 9}\left(i_{a}+i_{b}+i_{c}+i_{d}+i_{e}+i_{f}+i_{g}+i_{h}+i_{i}\right)
\end{gathered}
$$

In this case the obtained space vectors are:

$$
\begin{array}{ll}
\underline{i}_{\alpha \beta}=0 \quad \underline{i}_{x 1 y 1}=0 & \underline{i}_{x 3 y 3}=0 \\
\underline{i}_{x 2 y 2}=I(1-j 0.577) \cos (\omega t) & i_{0}=0
\end{array}
$$

As current does not flow in the torque producing $(\alpha-\beta)$ plane, there will be no torque produced by the machine in either charging or V2G modes. The only difference between charging and V2G modes is in the sign of the grid currents, leading to the opposite signs of the current components in the excited $x-y$ plane (and zero-sequence current in (4)).

\section{CONTROL AlgORITHM}

The conducted theoretical analysis suggests that the grid currents will lead to generation of only the non-torque producing current components. This means that the machine will impact on the current flow with its stator resistance and stator leakage inductance only, while there will be no back EMF. The inverter legs connected to the same three-phase winding are switched in the same instances in order to produce the same current in the respective machine phases.

Since the simplified scheme, shown in Fig. 2, can be considered, the control of the topology can be also simplified to the control of two equivalent inverter legs of the simplified circuit. A possible way of operation is to apply modulation signals in phase opposition to the two legs.

The control algorithm for single-phase charging and $\mathrm{V} 2 \mathrm{G}$ operation is shown in Fig. 3. The required feedback from the machine and inverter are the grid current, grid voltage and the dc-bus voltage. The grid voltage is fed to the phase-locked loop (PLL) block, shown in detail in Fig. 5. A resonant filter extracts the signal component that alternates at grid frequency. Further, a synchronous reference frame (SRF) PLL determines the position of this component and calculates its magnitude by feeding back the position to the rotational transformation. The position of the grid voltage obtained is used to create the reference current by calculating the cosine value of the angle and multiplying it with the desired current magnitude, as shown in Fig. 3.

The obtained sinusoidal value is compared in the current controller with the measured current and the control is executed according to Fig. 4. The output of the current controller is the reference voltage that will create a sufficient voltage drop on the machine's stator resistance and leakage inductance in order to realize the reference current.

The reference voltage contains an additional component that equals the grid voltage, enabling low currents at startup. This component is added to the reference voltage after the current controller (Fig. 3), before it is fed to the PWM block that generates the gating signals for the nine-phase inverter/rectifier.

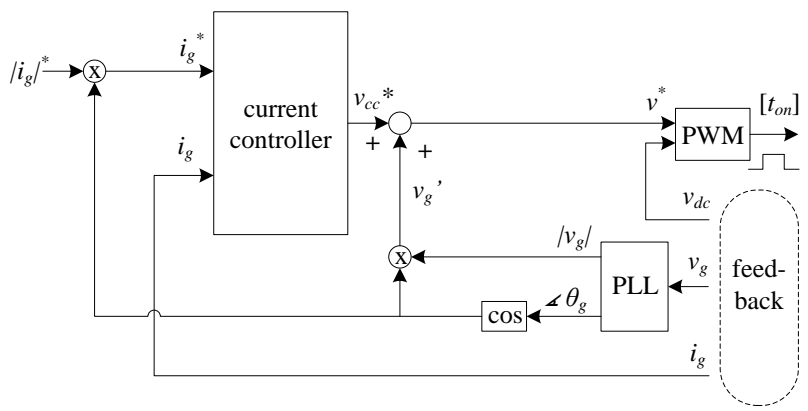

Fig. 3. Control algorithm for the single-phase charging $\left(\left|i_{g}\right|^{*}=\sqrt{2} I, i_{g}=i_{g^{+}}\right)$.

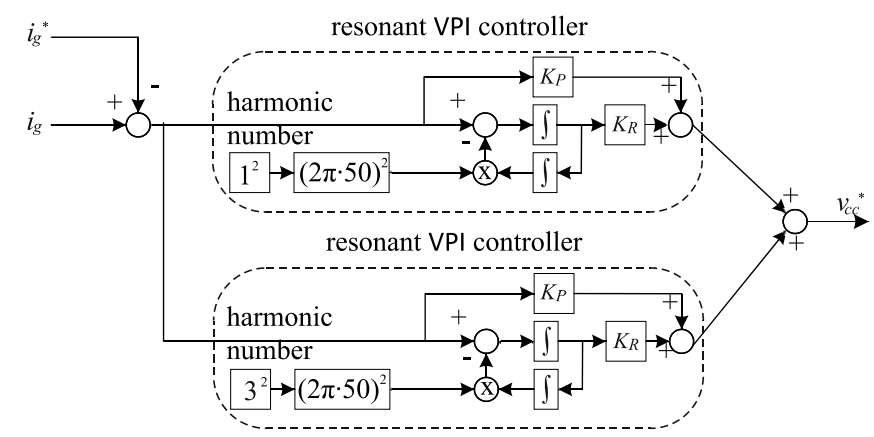

Fig. 4. Current controllers for the charging/V2G modes.

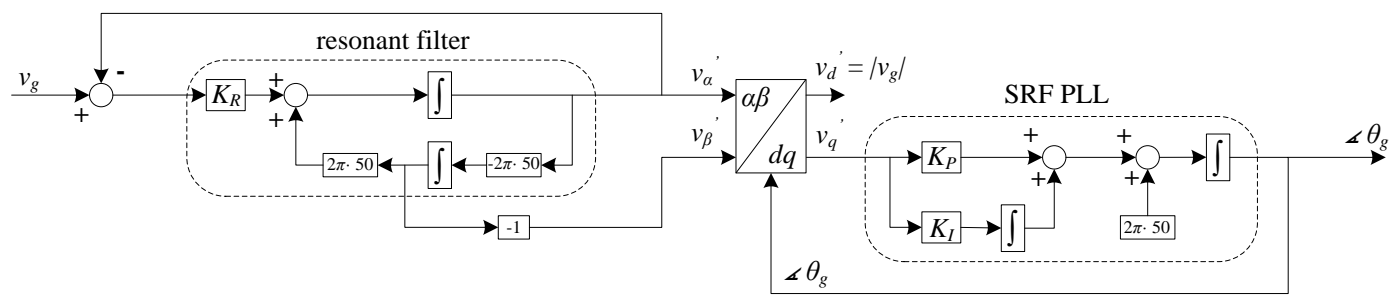

Fig. 5. Phase locked loop (PLL) algorithm (SRF stands for synchronous reference frame). 
The current controller is shown in detail in Fig. 4. It consists of resonant vector proportional-integral (VPI) controllers $[17,18]$. The VPI controller can be used for the regulation of the fundamental or any harmonic. Fig. 4 shows the case where one VPI controller controls the fundamental, and one controls the third harmonic. Similarly, several VPI controllers can be utilized for the control of low order harmonics, by connecting them in parallel in the same manner as shown in Fig. 4.

\section{Simulation Results}

The concept discussed so far is verified by means of simulations. The simulations were carried out in Simulink/SimPowerSystems toolbox. The battery is represented with a dc voltage source of $600 \mathrm{~V}$ and an internal resistance of $0.5 \Omega$ connected directly to the dc-bus of the nine-phase converter. The dc-dc converter is omitted, as already explained. The dc-bus capacitance of the inverter is set to $1.5 \mathrm{mF}$. A switching frequency of $10 \mathrm{kHz}$ is used with asymmetrical PWM, resulting in a sampling frequency of $20 \mathrm{kHz}$. The voltage drops of the semiconductor components are taken into account. Dead-time effect is neglected.

Both nine-phase machines have the following parameters: $R_{s}=6.5 \Omega, R_{r}=1.3 \Omega, L_{\gamma s}=25 \mathrm{mH}, L_{\gamma r}=15 \mathrm{mH}, L_{m}=1.3 \mathrm{H}$, one pole pair and rotor inertia $J=0.1 \mathrm{kgm}^{2}$; load torque is zero. Out of the three neutral points, one neutral of the nine-phase stator winding is connected to the neutral point of the grid and another is connected to a grid phase (Fig. 1). The applied grid phase voltage is taken as $240 \mathrm{~V}_{\mathrm{rms}}, 50 \mathrm{~Hz}$.

Results are provided for charging and vehicle-to-grid operation. A transition between charging and vehicle to grid operation is also shown. Most of the results are obtained with asymmetrical machine. Finally, the main differences that appear in the case of the symmetrical machine are illustrated.

\section{A. Steady State Operation with the Asymmetrical Machine}

The grid voltage and current are shown in Figs. 6 and 7 for charging and V2G operation, respectively. The operation with unity power factor at the grid side is evident and a certain amount of high-frequency ripple is present in the current waveform. The spectrum of the grid current, normalized with respect to the fundamental, is also provided in both figures. It can be seen from the zoomed low-frequency portions of the spectrum that the grid currents do not contain low order harmonics (all values are significantly below 1\%). The first switching frequency harmonics appear at and around $20 \mathrm{kHz}$. This is due to the PWM applied. The same carrier signal is used in both sets of three-phase windings connected to the grid, although the modulating signals are in phase opposition; thus, leg-to-leg voltage contains three levels and the harmonics around $10 \mathrm{kHz}$ cancel each other.

It is important to note that the torque produced by the machine is zero, Fig. 8. The rotor of the machine is therefore at standstill, as shown in Fig. 8.

Fig. 9 shows the machine's phase current and it's FFT. The harmonic distortion of this current is the same as the distortion of the grid phase current, since all three machine's phase currents that sum into one grid current are the same.
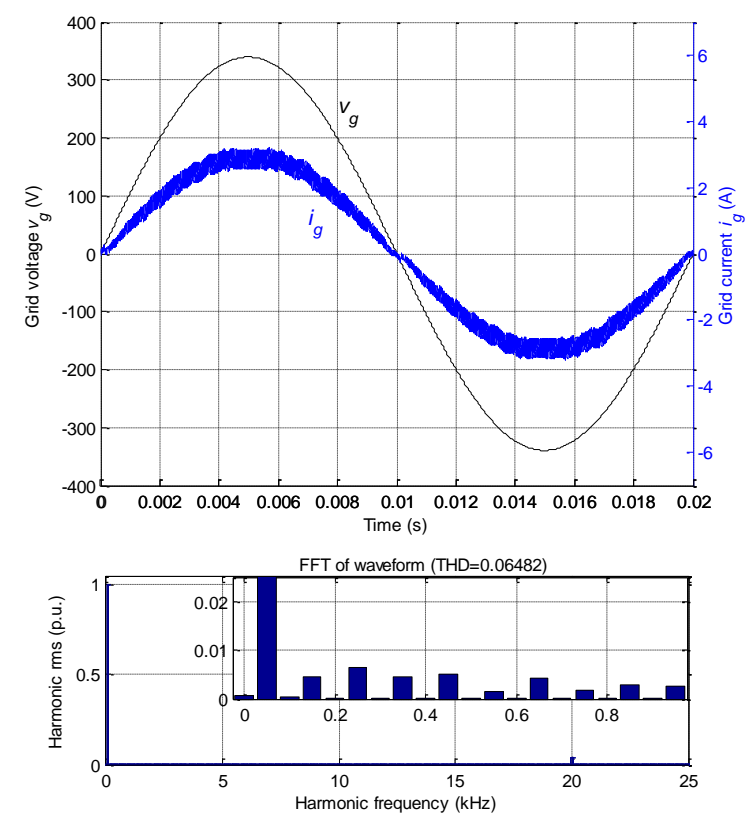

Fig. 6. Grid voltage waveform and grid current waveform with spectrum for charging mode of operation.
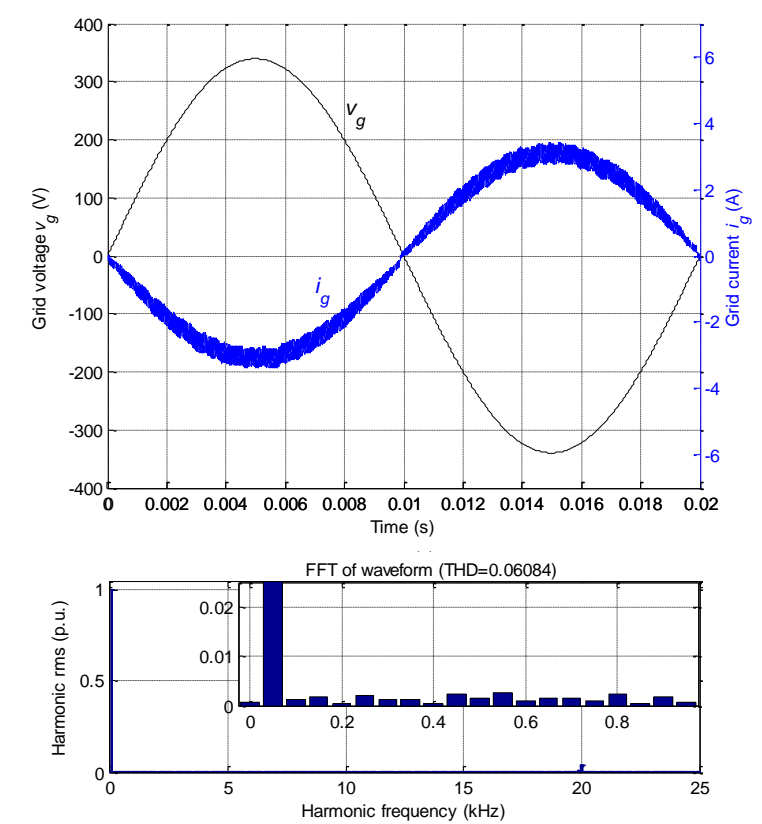

Fig. 7. Grid voltage waveform and grid current waveform with FFT for V2G mode of operation.

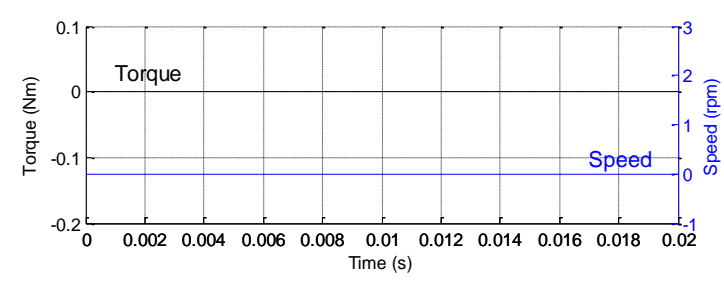

Fig. 8. Torque and speed of the machine. 

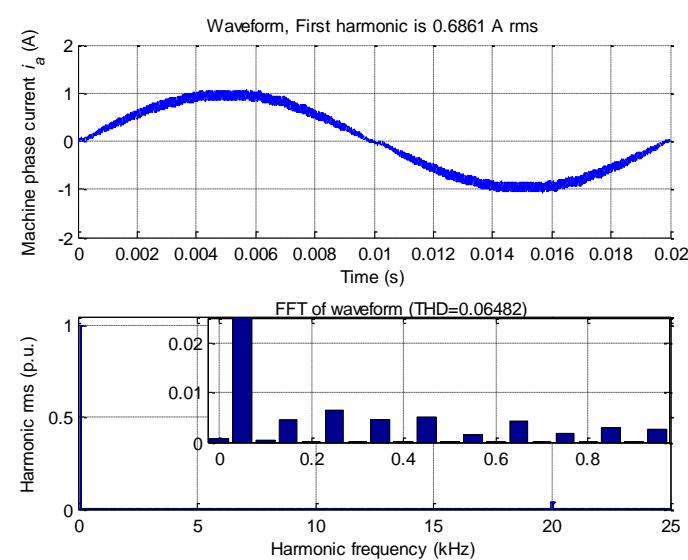

Fig. 9. Machine's phase current and spectrum for charging mode of operation.
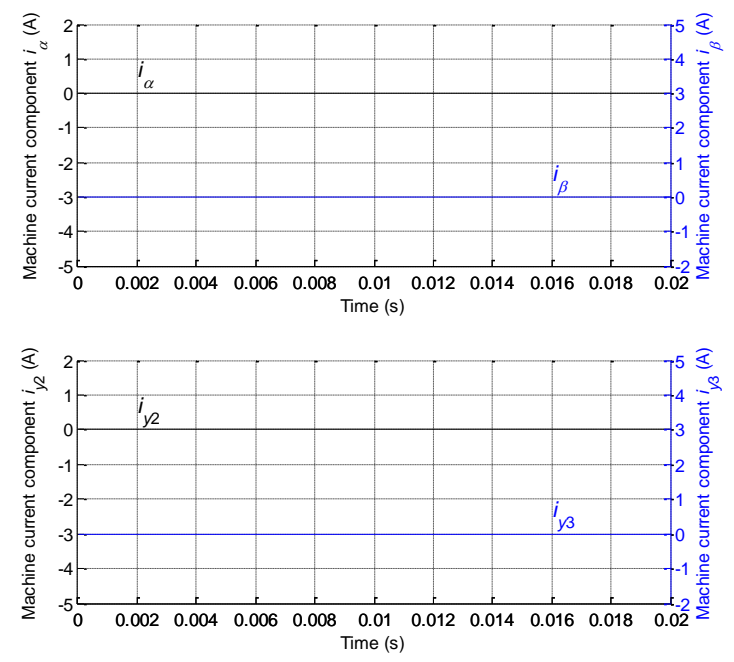

Fig. 10. Machine's current components $i_{\alpha}, i_{\beta}, i_{y 2}$ and $i_{y 3}$.

The machine currents in the planes, which should be of zero value according to (4), are $i_{\alpha}, i_{\beta}, i_{y 2}$ and $i_{y 3}$, and they are shown in Fig. 10. It can be seen that these planes are free from low order and high order harmonics as well. This is so because the three machine currents belonging to the same three-phase winding sets are exactly the same, and therefore cancel each other entirely in the decoupling transformation.

The machine current components that are of non-zero value according to (4) are shown in Fig. 11 for the charging mode of operation. These currents are $i_{x 1}, i_{y 1}$ and $i_{0}$. It can be seen that there is unequal current distribution in the $x_{1}-y_{1}$ plane, as predicted in (4). The non-zero components during the V2G mode are presented in Fig. 12, and it can be seen that the same components are excited. However, the components have the opposite sign compared to the charging mode.

The battery charging current and inverter dc-bus voltage are shown in Fig. 13 for charging and Fig. 14 for V2G mode of operation. The battery charging current is a sinusoidal waveform with a dc offset, since most of the power is delivered to the dc-bus when the grid current and grid voltage are at their positive or negative peak. When the grid voltage and

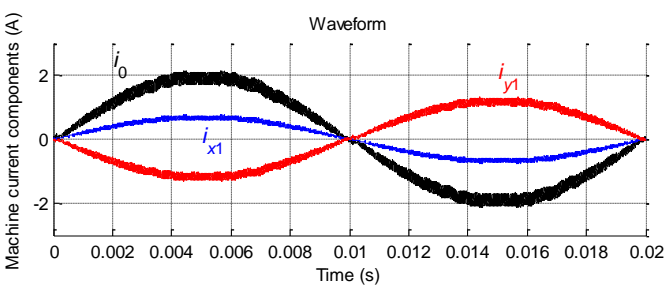

Fig. 11. Machine current components $i_{x 1}, i_{y 1}$ and $i_{0}$, in charging mode of operation.

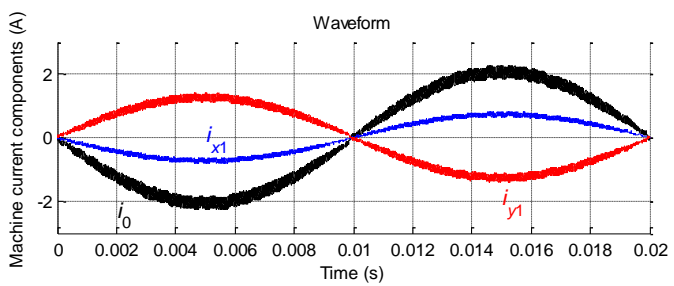

Fig. 12. Machine current components $i_{x 1}, i_{y 1}$ and $i_{0}$, in V2G mode of operation.

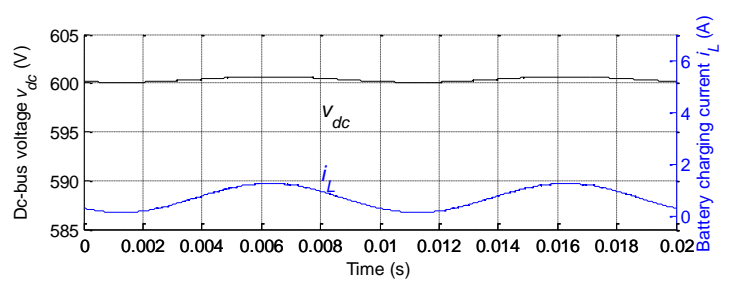

Fig. 13. Dc-bus voltage and battery charging current in charging mode of operation.

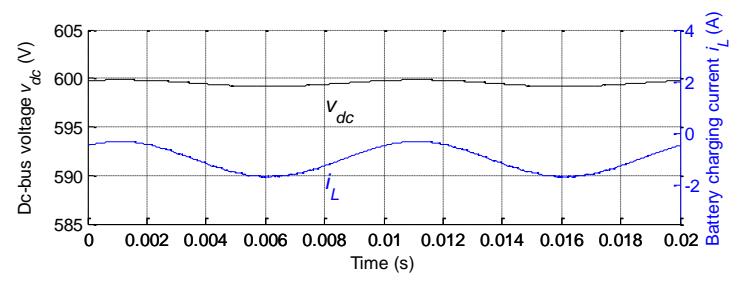

Fig. 14. Dc-bus voltage and battery charging current in V2G mode.

current are zero there is no power taken from the grid (see Fig. $6)$. This results in a fluctuating power flow to the battery.

The sinusoidal battery charging current causes a fluctuation of the dc-bus voltage by creating a voltage drop on the internal resistance of the battery. It can be noticed that, although the grid current amplitude is the same in charging and V2G modes, the dc-bus current has slightly higher dc component (by absolute value) in V2G mode. This is because the losses in the machine and converter are covered from the battery rather than from the grid.

\section{B. Transient Behaviour with the Asymmetrical Machine}

Simulations have also been conducted to illustrate the behavior of the system in transient mode of operation. The simulated dynamic regime starts in the charging mode with the grid current amplitude of 3A, and ends up in V2G mode with the grid current magnitude of -3A. Fig. 15 shows this transient. The grid current reference and actual values are shown in Fig. 15a and the machine phase current and battery charging current are shown in Fig. 15b. It can be seen that the transient happens practically instantaneously and that the 
currents retain roughly the same amount of distortion before and after the transient.

\section{Symmetrical Nine-phase Machine-Transient Behavior}

The majority of the results obtained with the symmetrical nine-phase machine during the steady state correspond with those obtained with the asymmetrical nine-phase machine, and are therefore not repeated here. The impedances of the two machines are the same in the torque producing and nonetorque producing planes as well. Therefore, the implemented control can be virtually the same, and in this subsection only transient regime from the charging to $\mathrm{V} 2 \mathrm{G}$ mode is considered.

Grid current and phase voltage are shown during the transient process in Fig. 16. The transient starts from the charging in a steady state, by changing the sign of the current reference. It can be seen that the grid current changes very fast from being in phase to being in counter-phase with the voltage, and keeps the same amplitude.

In Fig. 17 current components in inactive planes of the machine, according to (6), are shown. It can be seen that these planes are not excited during the transient. The plane in which current flows now is the $\mathrm{x} 2-\mathrm{y} 2$, as suggested by (6), and it can be seen from Fig. 18 that this is valid for charging as well as for $\mathrm{V} 2 \mathrm{G}$ mode.

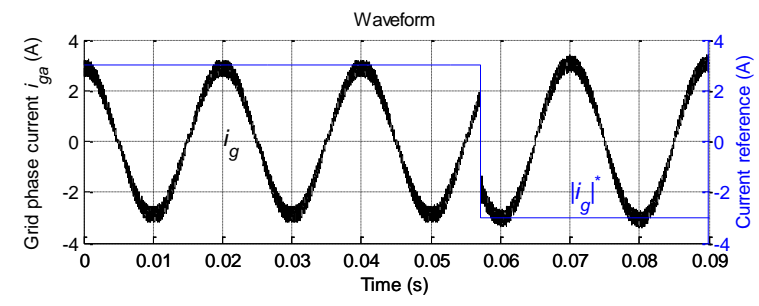

a)

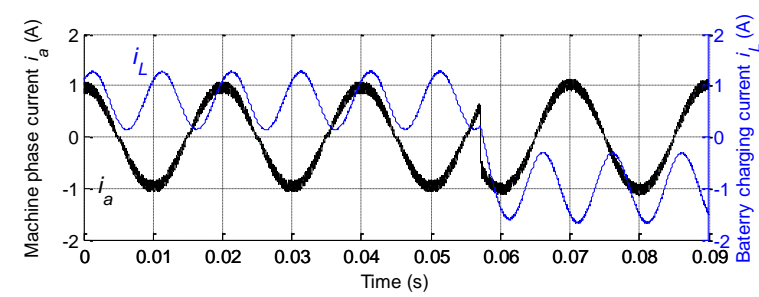

b)

Fig. 15. Tranient operation: a) Grid phase current and its magnitude reference $\left|i_{g}\right|^{*}$ and b) machine phase current and battery charging current for transition from charging $\left(i_{r e f}=3 \mathrm{~A}\right)$ to $\mathrm{V} 2 \mathrm{G}\left(i_{r e f}=-3 \mathrm{~A}\right)$ operation.

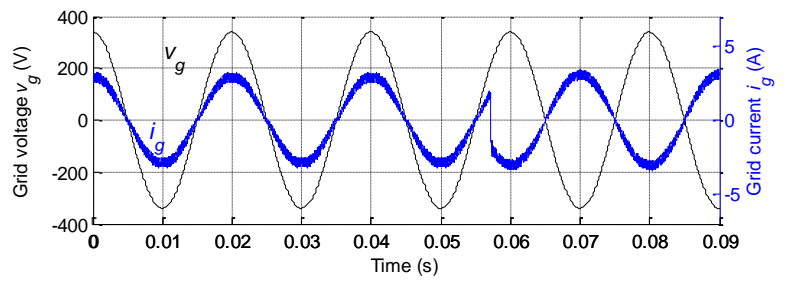

Fig. 16. Grid phase voltage and grid current during transition from the charging to V2G mode of operation.
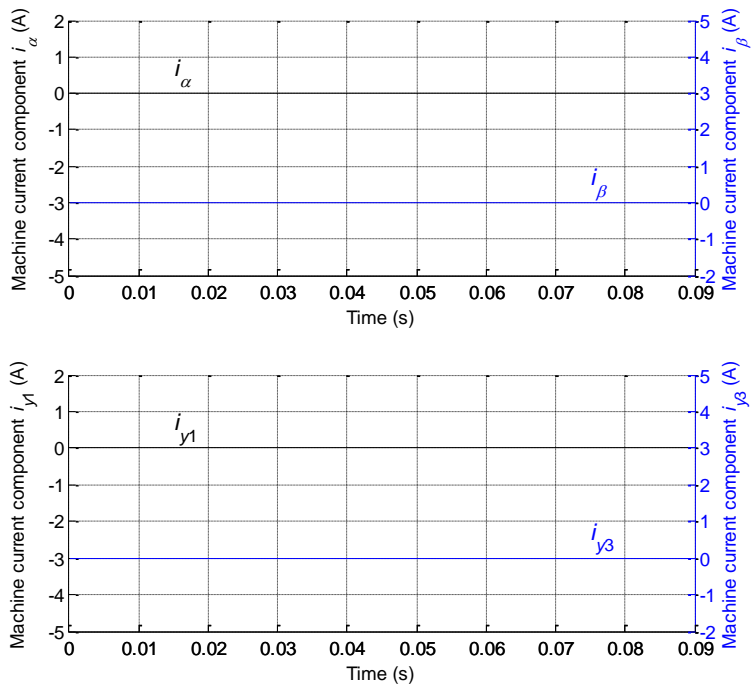

Fig. 17. Machine current components $i_{\alpha}, i_{\beta}, i_{y 1}$ and $i_{y 3}$ during the transient from the charging to $\mathrm{V} 2 \mathrm{G}$ mode of operation.

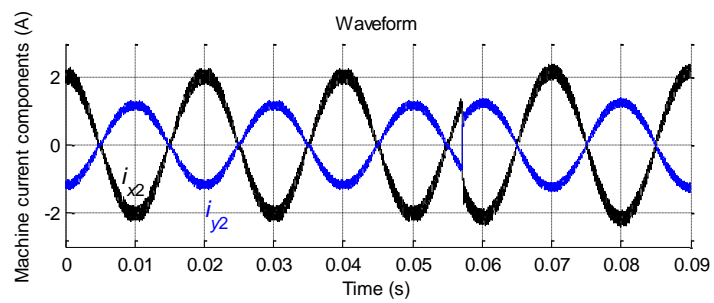

Fig. 18. Machine current components $i_{x 2}$ and $i_{y 2}$, during transition from charging to $\mathrm{V} 2 \mathrm{G}$ mode of operation.

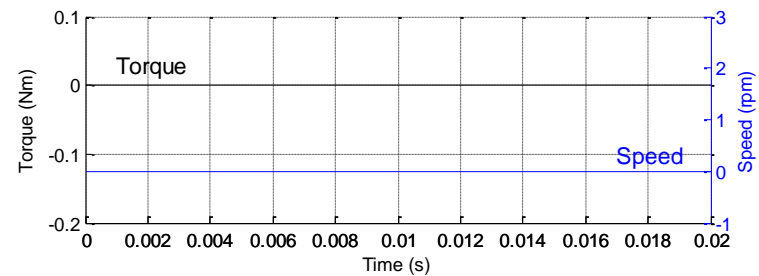

Fig. 19. Torque and speed of the machine during transition from the charging to V2G mode of operation.

The simulation is performed with a full model of the symmetrical nine-phase machine; thus its torque and speed can be observed during the whole transient process. This is presented in Fig. 19. It can be seen that even during the transient torque is not produced, since the currents in the machine windings belonging to the same three-phase set are the same, thus cancelling each other's effect.

\section{CONCLUSION}

The paper analyses means of charging an EV's battery from a single-phase source, using a nine-phase machine as a filter between the inverter and the grid. It extends the utilization possibilities of such a charger, previously proposed for threephase charging. The mathematical model of the single-phase charger is given. Simulations of the configuration performance demonstrate feasibility of charging and V2G operation with 
unity power factor and with zero torque production in the machine. It is shown that the charging principle is applicable with both symmetrical and asymmetrical nine-phase machine.

\section{REFERENCES}

[1] L. De Sousa, B. Silvestre, and B. Bouchez, "A combined multiphase electric drive and fast battery charger for electric vehicles," in Proc. IEEE Vehicle Power and Propulsion Conference VPPC, Lille, France, CD-ROM, 2010.

[2] P. Sandulescu, F. Meinguet, X. Kestelyn, E. Semail, and A. Bruyere, "Flux-weakening operation of open-end winding drive integrating a cost-effective high-power charger," IET Electrical Systems in Transportation, vol. 3, no. 1, pp. 10-21, 2013.

[3] I. Subotic, E. Levi, M. Jones, and D. Graovac, "An integrated battery charger for EVs based on an asymmetrical six-phase machine," in Proc. IEEE Ind. Elec. Soc. Conf. IECON, Vienna, Austria, pp. 7242-7247, 2013.

[4] I. Subotic, E. Levi, "An integrated battery charger for EVs based on a symmetrical six-phase machine," IEEE Int. Symp. on Ind. Electronics ISIE, in press, 2014.

[5] E. Levi, M. Jones, S. N. Vukosavic, and H. A. Toliyat, "A novel concept of a multiphase, multimotor vector controlled drive system supplied from a single voltage source inverter," IEEE Trans. on Power Electronics, vol. 19, no. 2, pp. 320-335, 2004.

[6] S. Loudot, B. Briane, O. Ploix, and A. Villeneuve, "Fast charging device for an electric vehicle," US Patent No. US 2012/0286740 A1, 2013.

[7] B. Briane and S. Loudot, "Rapid reversible charging device for an electric vehicle," US Patent No. US 2011/0254494 A1, 2011.

[8] I. Subotic, E. Levi, M. Jones, and D. Graovac, "On-board integrated battery chargers for electric vehicles using nine-phase machines," in Proc. IEEE Int. Electric Machines \& Drives Conf. IEMDC, Chicago, IL, pp. 226-233, 2013.

[9] S. Lacroix, E. Laboure, and M. Hilairet, "An integrated fast battery charger for electric vehicle," in Proc. IEEE Vehicle Power and Propulsion Conference VPPC, CD-ROM, 2010.

[10] D. Thimmesch, "An SCR inverter with an integral battery charger for electric vehicles," IEEE Trans. on Industry Applications, vol. IA-21, no. 4, pp. 1023-1029, 1985.

[11] A. G. Cocconi and W. E. Rippel, "Integrated motor drive and recharge system," US Patent No. US 5,099,186 A, 1992.

[12] A. G. Cocconi, "Combined motor drive and battery recharge system," US Patent No. US 5,341,075 A, 1994.

[13] S. Seung-Ki and L. Sang-Joon, "An integral battery charger for fourwheel drive electric vehicle," IEEE Trans. on Industry Applications, vol. 31, no. 5, pp. 1096-1099, 1995.
[14] L. Solero, "Nonconventional on-board charger for electric vehicle propulsion batteries," IEEE Trans. on Vehicular Technology, vol. 50, no. 1, pp. 144-149, 2001.

[15] L. Jianing, X. Guoqing, J. Linni, and L. Liu, "Electric air conditioner system with on-board charger for PHEV," in Proc. IEEE Int. Conf. on Information and Automation ICIA, Shenzhen, China, pp. 421-426, 2011.

[16] C. Hung-Chun and L. Chang-Ming, "An integrated driving/charging switched reluctance motor drive using three-phase power module," IEEE Trans. on Industrial Electronics, vol. 58, no. 5, pp. 1763-1775, 2011.

[17] C. Lascu, L. Asiminoaei, I. Boldea, and F. Blaabjerg, "High performance current controller for selective harmonic compensation in active power filters," IEEE Trans. on Power Electronics, vol. 22, no. 5, pp. 1826-1835, 2007.

[18] A. G. Yepes, "Digital resonant current controllers for voltage source converters." PhD Thesis, University of Vigo, 2011.

Nandor Bodo received his MSc degree in 2009 in Power Electronics from the University of Novi Sad, Faculty of Technical Sciences, Novi Sad, Serbia. He s obtained his $\mathrm{PhD}$ degree from the Liverpool John Moores University, UK in 2013. He is currently with Liverpool John Moores University as a postdoctoral research associate. His research interests include power electronics and variable speed drives.

Ivan Subotic received his MSc degree in Electrical Engineering from the University of Belgrade, Serbia in 2011. He is currently a PhD student at Liverpool John Moores University. His main research interests include power electronics and control of multiphase drive systems.

Emil Levi received his MSc and the $\mathrm{PhD}$ degrees from the University of Belgrade, Yugoslavia in 1986 and 1990, respectively. He joined Liverpool John Moores University, UK in May 1992 and is, since 2000, Professor of Electric Machines and Drives. He served as a Co-Editor-in-Chief of the IEEE Trans. on Industrial Electronics from 2009 until 2013, and is currently an Editor of the IEEE Trans. on Energy Conversion and Editor-in-Chief of the IET Electric Power Applications. He is a Fellow of the IEEE and the recipient of the Cyril Veinott "Electromechanical Energy Conversion Award" of the IEEE Power and Energy Society for 2009 and the Best Paper Award of the IEEE Trans. on Industrial Electronics for 2008.

Martin Jones received his BEng degree (First Class Honours) in Electrical Engineering from the Liverpool John Moores University, UK in 2001. He has been a research student at the Liverpool John Moores University from September 2001 till spring 2005, when he received his PhD degree. Dr Jones was a recipient of the IEE Robinson Research Scholarship for his PhD studies and is currently with Liverpool John Moores University as a Reader. His research is in the area of high performance ac drives. 